\title{
Avaliação de variedades de mandioca para consumo humano ${ }^{(1)}$
}

\author{
Maria de Fátima Borges ${ }^{(2)}$, Wânia Maria Gonçalves Fukuda( ${ }^{(3)}$ e Adroaldo Guimarães Rossetti(2)
}

\begin{abstract}
Resumo - Com o objetivo de identificar novas variedades para consumo humano, na forma de raízes frescas, 26 variedades de mandioca (Manihot esculenta, Crantz) foram avaliadas aos 8, 10 e 12 meses após o plantio, quanto à produtividade de raízes, teores de amido, de matéria seca e de cianeto, o tempo de cocção e à deterioração pós-colheita. A produtividade, os teores de amido e de matéria seca das raízes variaram entre as variedades, e entre as épocas de colheita. Aproximadamente, $81 \%$ das variedades continham teores de cianeto dentro dos limites aceitáveis (inferior a $100 \mathrm{mg} / \mathrm{kg}$ de polpa crua) para consumo na forma de raízes frescas (método enzimático). Apenas oito variedades cozinharam até 30 minutos em todas as épocas de colheita, nos dois anos de avaliação. A deterioração pós-colheita ocorreu em todas as variedades quando armazenadas sob condições ambiente. Houve correlação positiva entre a matéria seca e o amido $(\mathrm{r}=0,9826)$ e entre a época de colheita e o tempo de cocção $(\mathrm{r}=0,7304)$. Entre amido e o tempo de cocção a correlação foi negativa $(\mathrm{r}=-0,0570)$. As variedades Três meses e Caiabana são promissoras para consumo humano na forma de raízes frescas.
\end{abstract}

Termos para indexação: Manihot esculenta, matéria seca, amido, cocção, deterioração pós-colheita.

\section{Evaluation of cassava varieties for human consumption}

\begin{abstract}
This work aimed to select new cassava (Manihot esculenta Crantz) varieties for human consumption as fresh roots. A total of twenty six varieties were evaluated after eight, ten and twelve months after planting. Parameters were assessed as follow: root productivity, starch, dry matter and cyanide contents, cooking and post-harvest deterioration. Root productivity, starch and dry matter contents varied among varieties and among harvest period. Nearly $81 \%$ of the varieties presented cyanide content within the acceptable limits for consumption as fresh roots (less than $100 \mathrm{mg} / \mathrm{kg}$ of raw pulp), by the enzymatic method. Only eight varieties presented cooking up to 30 minutes during the experimental evaluation in all harvest period. All varieties tested behaved as susceptible to post-harvest deterioration when stored under environmental conditions. Correlations between starch and dry matter contents $(r=0.9826)$ and between harvest periods and cooking $(r=0.7304)$ were positive. Correlation between starch content and cooking was negative $(\mathrm{r}=-0.0570)$. Varieties Três meses and Caiabana were the best for human consumption as fresh roots.
\end{abstract}

Index terms: Manihot esculenta, dry matter, starch, cooking, post-harvest deterioration.

\section{Introdução}

A mandioca (Manihot esculenta, Crantz) de mesa, também conhecida como mandioca mansa, doce,

\footnotetext{
(1) Aceito para publicação em 16 de maio de 2002.

(2) Embrapa-Centro Nacional de Pesquisa de Agroindústria Tropical, Caixa Postal 3761, CEP 60511-110 Fortaleza, CE. E-mail: fatima@cnpat.embrapa.br, adroaldo@cnpat.embrapa.br

${ }^{(3)}$ Embrapa-Centro Nacional de Pesquisa de Mandioca e Fruticultura Tropical, Caixa Postal 007, CEP 44380-000 Cruz das Almas, BA. E-mail: wania@cnpmf.embrapa.br
}

aipim ou macaxeira (Conceição, 1983), é um dos alimentos preferenciais na mesa do brasileiro, principalmente nas Regiões Sudeste, Centro-Oeste e Nordeste.

Apesar do consumo de mandioca de mesa ser elevado, sua produção real é desconhecida, pois grande parte ocorre por exploração do tipo "fundo de quintal", e não passa por um processo organizado de comercialização (Pereira et al., 1985). A expansão do mercado de mandioca de mesa, no entanto, depende de variedades que apresentem boas qualidades culinárias, baixa toxicidade cianogênica e resistência à deterioração pós-colheita. 
A qualidade culinária de raízes frescas é um parâmetro importante na seleção de variedades de mandioca de mesa. A identificação dessa qualidade envolve fatores variados e complexos, por constituir-se de um conjunto de características físicas, químicas e sensoriais, algumas das quais são determinadas objetivamente, como teores de cianeto, amido e fibra, e tempo de cocção e, outras, subjetivamente, como sabor, consistência e textura da polpa cozida (Wheatley, 1987). O tempo de cozimento, bem como a massa cozida, apresenta variações entre raízes de uma mesma cultivar (Fukuda \& Borges, 1988; Borges et al., 1992). Estudos revelaram que este fator varia com o tipo de solo, variedade e idade da planta (Borges \& Fukuda, 1989; Fukuda \& Borges, 1990). O tempo de cozimento de raízes de boa qualidade culinária não deve ser superior a 30 minutos e a polpa cozida deve ser facilmente esmagada e desfeita, quando amassada com um garfo, formando uma pasta de textura farinácea, consistência plástica e moldável (Wheatley, 1987; Borges et al., 1992).

O consumo de mandioca de mesa tem sido limitado, em parte, por sua toxicidade cianogênica (cianeto), a qual depende, principalmente, do teor de glicosídios cianogênicos (linamarina e lotaustralina) presentes nos tecidos da planta, que, ao hidrolisaram-se por ação enzimática (linamarase), desdobram-se em ácido cianídrico (Conn, 1969).

O grupo de variedades de mandioca mansa caracteriza-se, principalmente, por apresentar teores de cianeto abaixo de $100 \mathrm{mg} / \mathrm{kg}$ de polpa nas raízes frescas (Bolhuis, 1954). Esses componentes variam substancialmente em razão da variedade e, em menor escala, das condições de cultivo, época de colheita e condições ambientais (Santamaria Hernandez \& Contreras Guillen, 1984; Fukuda et al., 1988; Borges \& Fukuda, 1989; Fukuda \& Borges, 1990; Borges et al., 1993). As variedades com concentrações de cianeto na raiz fresca acima de $100 \mathrm{mg} / \mathrm{kg}$ de peso são denominadas bravas ou venenosas (Bolhuis, 1954), ou seja, impróprias para consumo fresco, sendo, portanto, indicadas para a indústria, onde a toxicidade da raiz é reduzida durante o processamento. No preparo de produtos derivados da mandioca de mesa, como mandioca cozida, frita, bolo, purê, suflê, entre outros, o cianeto presente na polpa também é desprendido por volatilização atin- gindo níveis baixíssimos, tornando-os inócuos. Borges \& Fukuda (1989) verificaram que a cocção e a fritura proporcionaram redução substancial do conteúdo de cianeto da polpa, variando pela cocção entre 56 e $80 \%$ e, pela fritura, entre 70 a $82 \%$. Djazuli \& Bradbury (1999) também constataram que a cocção reduz o teor de cianeto das raízes a níveis seguros para consumo, permitindo seu uso na alimentação.

Outro fator que também afeta a comercialização e o consumo de raízes frescas de mandioca de mesa, principalmente nos centros urbanos, é a rápida deterioração pós-colheita que se manifesta com a perda da qualidade e quantidade das raízes, sendo resultante de danos mecânicos, fisiológicos e microbiológicos. Os danos fisiológicos, considerados primários, iniciam-se durante as primeiras 24 a 72 horas após a colheita, enquanto os danos microbiológicos, considerados secundários, ocorrem do quinto ao sétimo dia após a colheita (Booth, 1976; Jansen \& Wheatley, 1985; Wheattley, 1987). A resistência à deterioração pós-colheita pode ser controlada geneticamente, pela seleção de variedades mais resistentes, permitindo ampliar o tempo de conservação das raízes após a colheita (Montaldo, 1973; Booth, 1974; Fukuda et al., 1988). Outra alternativa para minimizar as perdas por deterioração pós-colheita tem sido o emprego de técnicas de conservação in natura de raízes frescas (Carvalho et al., 1982a, 1982b; Wheatley, 1987; Kato, 1988; Sargent et al., 1995). Entretanto, em termos comerciais, essas técnicas têm sido pouco utilizadas.

O objetivo deste trabalho foi identificar e selecionar novas variedades de mandioca para consumo humano na forma de raízes frescas.

\section{Material e Métodos}

O estudo foi realizado nos anos agrícolas 1990/1991 e 1991/1992 e as variedades avaliadas foram selecionadas do Banco Ativo de Germoplasma de Mandioca (BGM) da Embrapa-Centro Nacional de Pesquisa de Mandioca e Fruticultura Tropical, em Cruz das Almas, BA, com precipitação média de $1.200 \mathrm{~mm}$, temperatura média de $24^{\circ} \mathrm{C}$ e umidade relativa em torno de $80 \%$. Os solos são do tipo Latossolo Vermelho-Amarelo, com textura média e baixa fertilidade. $\mathrm{O} \mathrm{pH}$ varia de 4,5 a 5,0.

O delineamento experimental foi o de blocos ao acaso em parcela subdividida, com três repetições, sendo as par- 
celas constituídas por 26 variedades e as subparcelas por três épocas de colheita (8, 10, e 12 meses após o plantio). Cada parcela era constituída por 77 plantas e as subparcelas por nove plantas, com espaçamento de 1,00x0,60 m.

As variedades avaliadas foram selecionadas com base em seus baixos teores de cianeto (inferiores a $100 \mathrm{mg} / \mathrm{kg}$ de polpa crua). A colheita das raízes foi realizada aos 8,10 e 12 meses após o plantio. Foram avaliadas a produtividade, os teores de matéria seca, de amido e de cianeto, o tempo de cocção e a deterioração pós-colheita.

Aos 8, 10 e 12 meses após o plantio, nove plantas úteis de cada parcela foram colhidas e pesadas para obtenção da produtividade de raízes (t/ha). Nessas plantas foram determinados os teores de matéria seca e de amido na raiz em amostras de $5 \mathrm{~kg}$ de raízes frescas pelo método da balança hidrostática (Grossman \& Freitas, 1950). O teor de cianeto foi determinado em amostras de raízes colhidas aos 10 meses após o plantio, por meio dos métodos titulométrico (Teles, 1972) e enzimático de Cooke, modificado por O’Brien et al. (1991).

A cocção foi avaliada aos 8, 10 e 12 meses após o plantio, mediante determinação do tempo de cocção da polpa crua. Pedaços de $5 \mathrm{~cm}$ de polpa, de três raízes de cada variedade, foram colocados em água fervente e, periodicamente, eram espetados com um garfo para verificar o grau de cozimento e determinar o tempo de cocção. A cocção foi considerada adequada, quando o cozimento da polpa ocorreu, em no máximo 30 minutos, após a imersão na água fervente (Wheatley, 1987).

A deterioração pós-colheita foi avaliada em raízes colhidas aos 10 meses após o plantio, para verificar o período de conservação das mesmas após a colheita, do primeiro ao sexto dia de armazenamento, sob condições ambiente. Diariamente, um lote de dez raízes foi cortado em rodelas finas para determinação da porcentagem de deterioração fisiológica observada ao longo das raízes, conforme uma escala de notas de zero (ausência de deterioração) a cinco (100\% de deterioração), proposta por Wheatley (1987).

Os dados obtidos foram submetidos à análise de variância e segundo o modelo de parcela subdividida, com exceção das variáveis teor de cianeto e deterioração póscolheita, as quais foram avaliadas apenas aos 10 meses após o plantio; as médias foram comparadas pelo teste de Tukey, a $5 \%$ de probabilidade.

\section{Resultados e Discussão}

Os teores de amido e de matéria seca e a produtividade das raízes variaram significativamente entre as variedades (Tabela 1), assim como entre os anos agrícolas e as épocas de colheita (Tabela 2). Onze variedades destacaram-se pelo elevado teor de amido $(30,86 \%$ a $33,55 \%)$ e de matéria seca $(35,59 \%$ a $38,20 \%$ ) e pela boa produtividade (18,73 a 25,31t/ha). Os coeficientes de correlação baixos e não significativos entre os teores de matéria seca e de amido com a produtividade de raízes, respectivamente $(r=0,0814$ e $r=0,0549)$, indicam não haver relação direta entre essas variáveis. Fukuda \& Borges (1991) também observaram que os teores de amido e de farinha não apresentaram correlações significativas com o rendimento de raízes.

Em relação à época de colheita, as variedades apresentaram menor teor de amido e de matéria seca aos 10 meses enquanto a produtividade aumentou de forma crescente até os 12 meses após o plantio (Tabela 2).

A variação do teor de cianeto entre os anos não foi significativa. Pelo método titulométrico, os teo-

Tabela 1. Média dos teores de amido, de matéria seca e da produtividade de raízes de mandioca, nos anos agrícolas de 1990/1991 e 1991/1992. Cruz das Almas, BA(1).

\begin{tabular}{llll}
\hline Variedade & \multicolumn{1}{c}{$\begin{array}{c}\text { Amido } \\
(\%)\end{array}$} & $\begin{array}{c}\text { Matéria seca } \\
(\%)\end{array}$ & $\begin{array}{c}\text { Produtividade } \\
(\mathrm{t} / \mathrm{ha})\end{array}$ \\
\hline Amansa burro & $33,55 \mathrm{a}$ & $38,20 \mathrm{a}$ & $20,16 \mathrm{abcdef}$ \\
CM-424/1 & $32,65 \mathrm{ab}$ & $37,65 \mathrm{ab}$ & $19,65 \mathrm{abcdef}$ \\
Canário & $32,27 \mathrm{abc}$ & $36,92 \mathrm{abc}$ & $18,60 \mathrm{bcdefg}$ \\
Caiabana & $32,10 \mathrm{abc}$ & $36,76 \mathrm{abc}$ & $17,95 \mathrm{cdefg}$ \\
Três meses & $31,87 \mathrm{abcd}$ & $36,42 \mathrm{bcde}$ & $23,11 \mathrm{abcd}$ \\
Arizoninha branca & $31,89 \mathrm{abcd}$ & $36,54 \mathrm{bcd}$ & $17,46 \mathrm{defg}$ \\
Aipim abacate & $31,96 \mathrm{abcd}$ & $36,73 \mathrm{abc}$ & $16,93 \mathrm{efg}$ \\
Caravela & $31,73 \mathrm{bcde}$ & $36,35 \mathrm{bcde}$ & $16,62 \mathrm{fgh}$ \\
Cachoeiro & $31,37 \mathrm{bcdef}$ & $36,02 \mathrm{cdef}$ & $24,10 \mathrm{ab}$ \\
Franco Rabelo & $31,23 \mathrm{bcdefg}$ & $35,99 \mathrm{cdefg}$ & $20,21 \mathrm{abcdef}$ \\
PI-939 & $30,86 \mathrm{cdefgh}$ & $35,59 \mathrm{cdefgh}$ & $18,95 \mathrm{bcdef}$ \\
Matrincha & $30,75 \mathrm{cdefgh}$ & $35,11 \mathrm{defghi}$ & $8,05 \mathrm{i}$ \\
Saracura & $30,22 \mathrm{defghi}$ & $34,84 \mathrm{efghij}$ & $23,99 \mathrm{abc}$ \\
Maragogipe & $30,08 \mathrm{efghi}$ & $34,74 \mathrm{fghij}$ & $15,22 \mathrm{fgh}$ \\
Manso & $29,75 \mathrm{fghij}$ & $34,40 \mathrm{ghijk}$ & $17,79 \mathrm{defg}$ \\
Taquari & $29,51 \mathrm{ghijk}$ & $34,00 \mathrm{hijkl}$ & $24,49 \mathrm{ab}$ \\
Cabocla & $29,52 \mathrm{ghijk}$ & $34,22 \mathrm{khij}$ & $10,83 \mathrm{hi}$ \\
Pão II & $29,28 \mathrm{hijkl}$ & $33,68 \mathrm{ijkl}$ & $17,60 \mathrm{defg}$ \\
SM-82/1 & $28,58 \mathrm{ijkl}$ & $33,23 \mathrm{jkl}$ & $22,83 \mathrm{abcde}$ \\
Arrebenta burro & $28,81 \mathrm{ijkl}$ & $33,46 \mathrm{jkl}$ & $18,73 \mathrm{bcdefg}$ \\
Sabará & $28,95 \mathrm{ijkl}$ & $33,60 \mathrm{ijkl}$ & $16,70 \mathrm{fgh}$ \\
Manteiga & $28,29 \mathrm{jkl}$ & $32,94 \mathrm{kl}$ & $18,03 \mathrm{cdefg}$ \\
Cenoura rosada & $27,78 \mathrm{klm}$ & $32,44 \mathrm{~lm}$ & $13,44 \mathrm{ghi}$ \\
CM-305/1 & $27,75 \mathrm{~lm}$ & $32,561 \mathrm{~m}$ & $14,78 \mathrm{fgh}$ \\
MCOL 113 & $26,36 \mathrm{mn}$ & $31,01 \mathrm{mn}$ & $16,17 \mathrm{fgh}$ \\
IAC-12-442 & $24,89 \mathrm{n}$ & $29,54 \mathrm{n}$ & $25,31 \mathrm{a}$ \\
\hline
\end{tabular}

${ }^{(1)}$ Em cada coluna, médias seguidas da mesma letra não diferem entre si pelo teste de Tukey, a $5 \%$ de probabilidade. 
res de cianeto encontraram-se dentro dos limites aceitáveis para consumo fresco (abaixo de $100 \mathrm{mg} / \mathrm{kg}$ de polpa crua), enquanto pelo método enzimático quatro variedades apresentaram teores acima de $100 \mathrm{mg} / \mathrm{kg}$ de polpa crua, sendo, portanto, consideradas impróprias para consumo na forma de raízes frescas (Tabela 3 ), segundo a classificação de Bolhuis (1954), enfatizada por Pereira et al. (1985), Normanha (1988) e Lorenzi et al. (1993). As variedades Três meses, Franco Rabelo, PI-939 e Cabocla apresentaram os menores teores de cianeto (inferior a $50 \mathrm{mg} / \mathrm{kg}$, método enzimático) e, portanto, podem ser consideradas inócuas, segundo a classificação de Bolhuis (1954).

O método enzimático (35,23 mg/kg a 209,36 mg/kg) foi mais eficiente na quantificação do cianeto das raízes uma vez que, em média, sua precisão foi $50 \%$ superior a do método titulométrico $(22,33 \mathrm{mg} / \mathrm{kg}$ a $92,00 \mathrm{mg} / \mathrm{kg}$ ). Houve alta correlação entre os dados obtidos nos dois métodos $(\mathrm{r}=0,9826)$. Resultados semelhantes foram constatados por Borges et al. (1993), quando avaliaram três métodos para determinação de cianeto em raiz de mandioca. Até o momento, não foi desenvolvido um método que seja rápido, preciso e de baixo custo para determinação quantitativa do teor de cianeto em mandioca e produtos derivados. Esses fatores têm sido um entrave em estudos de melhoramento genético de mandioca para seleção de variedades com baixo teor de cianeto, por causa do grande número de genótipos avaliados. O método titulométrico tem sido empregado pela sua simplicidade e baixo custo, porém apresenta hidrólise incompleta dos glicosídios cianogênicos e baixa recuperação do ácido cianídrico. O método enzimático

Tabela 2. Média dos teores de amido, de matéria seca e da produtividade de raízes de mandioca, em três épocas de colheita, nos anos agrícolas de 1990/1991 e 1991/1992. Cruz das Almas, BA ${ }^{(1)}$.

\begin{tabular}{cccc}
$\begin{array}{c}\text { Epoca de colheita } \\
(\text { mês })\end{array}$ & $\begin{array}{c}\text { Amido } \\
(\%)\end{array}$ & $\begin{array}{c}\text { Matéria seca } \\
(\%)\end{array}$ & $\begin{array}{c}\text { Produtividade } \\
(\mathrm{t} / \mathrm{ha})\end{array}$ \\
\hline $8^{\circ}$ & $30,25 \mathrm{a}$ & $34,93 \mathrm{a}$ & $15,07 \mathrm{c}$ \\
$10^{\circ}$ & $29,80 \mathrm{~b}$ & $34,39 \mathrm{~b}$ & $18,51 \mathrm{~b}$ \\
$12^{\circ}$ & $30,18 \mathrm{a}$ & $34,86 \mathrm{a}$ & $21,55 \mathrm{a}$ \\
\hline Ano agrícola de 1990/1991 & $19,00 \mathrm{a}$ & $34,14 \mathrm{a}$ & $29,47 \mathrm{a}$ \\
Ano agrícola de 1991/1992 & $17,74 \mathrm{~b}$ & $35,31 \mathrm{~b}$ & $30,68 \mathrm{~b}$ \\
\hline (1) Em cada coluna, médias seguidas da mesma letra não diferem entre si pelo \\
teste de Tukey, a 5\% de probabilidade.
\end{tabular}

permite analisar tanto a mandioca fresca como a processada, pois os glicosídios cianogênicos são hidrolisados pela adição da enzima linamarase purificada e o cianeto livre e o total são quantificados colorimetricamente.

O fator genético tem sido considerado como uma das principais causas de variação do teor de cianeto em variedades de mandioca (Fukuda et al., 1988; Borges et al., 1993; Lorenzi et al., 1993; Wheatley et al., 1993). Em estudo realizado com 206 variedades de mandioca cultivadas em quintais do Estado de São Paulo, Lorenzi et al. (1993) observaram ampla variação nos teores de cianeto (16 mg/kg a $482 \mathrm{mg} / \mathrm{kg}$ ), com $33 \%$ das cultivares apresentando teores de cianeto superiores a $100 \mathrm{mg} / \mathrm{kg}$ de polpa crua. Os resultados dessa pesquisa causaram surpresa considerando-se que o material analisado correspondeu a variedades de mandioca destinadas, exclusivamente, ao consumo humano na forma de raízes frescas.

Tabela 3. Média dos teores de cianeto em raízes de mandioca, aos dez meses de plantio, analisadas pelos métodos titulométrico e enzimático, e eficiência relativa, nos anos agrícolas de 1990/1991 e 1991/1992. Cruz das Almas, BA ${ }^{(1)}$.

\begin{tabular}{llll}
\hline Variedade & $\begin{array}{c}\text { Método } \\
\text { titulométrico }\end{array}$ & $\begin{array}{c}\text { Método } \\
\text { enzimático }\end{array}$ & $\begin{array}{c}\text { Eficiência } \\
(\%)\end{array}$ \\
\hline Cenoura rosada & $92,00 \mathrm{a}$ & $209,36 \mathrm{a}$ & 43,9 \\
Amansa burro & $60,75 \mathrm{~b}$ & $108,71 \mathrm{~cd}$ & 55,9 \\
Canário & $58,50 \mathrm{bc}$ & $135,73 \mathrm{~b}$ & 43,1 \\
Aipim abacate & $51,75 \mathrm{bcd}$ & $106,89 \mathrm{~cd}$ & 48,4 \\
Pão II & $47,25 \mathrm{bcde}$ & $88,29 \mathrm{defg}$ & 53,5 \\
Cachoeiro & $45,00 \mathrm{bcdef}$ & $65,56 \mathrm{ghijk}$ & 68,6 \\
MCOL 113 & $42,75 \mathrm{bcdefg}$ & $96,91 \mathrm{cde}$ & 44,1 \\
Maragogipe & $42,75 \mathrm{bcdefg}$ & $95,71 \mathrm{cde}$ & 44,7 \\
Manso & $42,75 \mathrm{bcdefg}$ & $76,41 \mathrm{efgh}$ & 55,9 \\
Taquari & $38,25 \mathrm{cdefg}$ & $74,08 \mathrm{efghi}$ & 51,6 \\
Saracura & $36,00 \mathrm{defg}$ & $74,22 \mathrm{efghi}$ & 48,5 \\
Arrebenta burro & $36,00 \mathrm{defg}$ & $53,85 \mathrm{hijlk}$ & 66,8 \\
Caiabana & $33,75 \mathrm{defg}$ & $72,15 \mathrm{efghi}$ & 46,8 \\
Matrincha & $31,50 \mathrm{defg}$ & $53,21 \mathrm{hijkl}$ & 59,2 \\
CM-424/1 & $31,50 \mathrm{defg}$ & $66,76 \mathrm{fghij}$ & 47,2 \\
Arizoninha branca & $29,25 \mathrm{efg}$ & $92,94 \mathrm{cdef}$ & 31,5 \\
Manteiga & $29,25 \mathrm{efg}$ & $51,25 \mathrm{klhij}$ & 57,1 \\
CM-305/1 & $29,25 \mathrm{efg}$ & $115,63 \mathrm{bc}$ & 25,3 \\
Sabará & $27,00 \mathrm{efg}$ & $62,54 \mathrm{ghijk}$ & 43,2 \\
IAC-12-442 & $27,00 \mathrm{efg}$ & $62,34 \mathrm{ghijk}$ & 43,3 \\
Três meses & $24,75 \mathrm{fg}$ & 35,231 & 70,2 \\
Cabocla & $22,57 \mathrm{~g}$ & $48,99 \mathrm{ijkl}$ & 46,1 \\
SM-82/1 & $22,50 \mathrm{~g}$ & $51,65 \mathrm{hijkl}$ & 43,5 \\
Franco Rabelo & $22,50 \mathrm{~g}$ & $39,78 \mathrm{kl}$ & 56,5 \\
Caravela & $22,50 \mathrm{~g}$ & $57,28 \mathrm{hijkl}$ & 39,3 \\
PI-939 & $22,33 \mathrm{~g}$ & $41,12 \mathrm{jkl}$ & 54,3 \\
\hline
\end{tabular}

${ }^{(1)}$ Em cada coluna, médias seguidas da mesma letra não diferem entre si pelo teste de Tukey, a 5\% de probabilidade. ${ }^{(2)}$ Eficiência $=100$ [Teor de cianeto (método titulométrico)/Teor de cianeto (método enzimático)]. 
A identificação de variedades de mandioca com baixos teores de cianeto da polpa crua das raízes é necessária a fim de aumentar a segurança das recomendações destas para alimentação humana, diminuindo-se os riscos de intoxicação dos consumidores. Por isso, destaca-se a relevância de programas de melhoramento genético que visam à identificação e seleção de novas variedades de mandioca para consumo na forma de raízes frescas, sem ou com baixos teores de cianeto. $\mathrm{O}$ uso de cultivares com baixo teor de cianeto propicia a obtenção de produtos derivados com níveis de cianeto $(20 \mathrm{mg} / \mathrm{kg}$ ) seguros para consumo humano (Almazan, 1986; Edijala et al., 1999).

Quanto ao período de cocção, não foi detectado diferença significativa entre os anos agrícolas e entre as épocas de colheita, mas foram observadas diferenças entre as variedades, nas médias dos anos e das épocas de colheita (Tabela 4).

Entre as 26 variedades avaliadas, 18 apresentaram cocção adequada, isto é, até 30 minutos, mas somente oito variedades apresentaram cozimento

Tabela 4. Média do tempo de cocção de raízes de mandioca, nos anos agrícolas de 1990/1991 e 1991/1992. Cruz das Almas, $\mathrm{BA}^{(1)}$.

\begin{tabular}{|c|c|}
\hline Variedade $^{(2)}$ & $\begin{array}{l}\text { Tempo de cocção } \\
\text { (min.) }\end{array}$ \\
\hline PI-939 & $30,00 \mathrm{a}$ \\
\hline Canário & $29,00 \mathrm{a}$ \\
\hline Cachoeiro & $29,00 \mathrm{a}$ \\
\hline CM-424/1 & $28,00 \mathrm{a}$ \\
\hline Caravela $^{(2)}$ & $26,73 \mathrm{ab}$ \\
\hline Cenoura rosada & $26,67 \mathrm{ab}$ \\
\hline SM-82/1 & $26,33 \mathrm{ab}$ \\
\hline Cabocla $^{(2)}$ & $26,04 \mathrm{ab}$ \\
\hline Saracura $^{(2)}$ & $25,47 \mathrm{ab}$ \\
\hline Taquari & $24,83 \mathrm{ab}$ \\
\hline Maragogipe $^{(2)}$ & $24,57 \mathrm{ab}$ \\
\hline Manteiga $(2)$ & $24,47 \mathrm{ab}$ \\
\hline Caiabana $^{(2)}$ & $24,40 \mathrm{ab}$ \\
\hline Arrebenta burro & $24,33 \mathrm{ab}$ \\
\hline Manso $^{(2)}$ & $23,57 \mathrm{ab}$ \\
\hline Pão II & $23,00 \mathrm{ab}$ \\
\hline Três meses ${ }^{(2)}$ & $22,30 \mathrm{ab}$ \\
\hline CM-305/1 & $19,33 b$ \\
\hline
\end{tabular}

${ }^{(1)}$ Em cada coluna, médias seguidas da mesma letra não diferem entre si pelo teste de Tukey, a $5 \%$ de probabilidade. ${ }^{(2)}$ Tempo de cozimento adequado nas três épocas de colheita. adequado aos 8, 10 e 12 meses após o plantio. Em outros estudos de seleção de variedades para consumo na forma de raízes frescas foram encontradas diferenças na cocção de raízes de mandioca, não só entre as variedades, mas também entre épocas de colheita (Pereira et al., 1985; Fukuda \& Borges, 1988; Fukuda et al., 1988).

A deterioração pós-colheita das raízes diferiu entre as variedades após o sexto dia de armazenamento e variou entre $46,64 \%$ e $89,36 \%$, mostrando que todas as variedades foram suscetíveis à deterioração pós-colheita, quando armazenadas sob condições ambiente (Tabela 5). No entanto, Montaldo (1973), Booth (1974) e Fukuda et al. (1988) constataram que a resistência de raízes de mandioca à deterioração pós-colheita pode ser controlada geneticamente, pela seleção de variedades mais resistentes.

Tabela 5. Média da porcentagem de deterioração (\%) póscolheita de raízes de mandioca, aos dez meses após o plantio, armazenadas durante seis dias em temperatura ambiente, nos anos agrícolas de 1990/1991 e 1991/1992. Cruz das Almas, $\mathrm{BA}^{(1)}$.

\begin{tabular}{|c|c|c|c|}
\hline Variedade $^{(2)}$ & $\begin{array}{c}\text { Nos dois } \\
\text { anos }\end{array}$ & $1990 / 1991$ & $1991 / 1992$ \\
\hline Arizoninha branca & $89,36 \mathrm{a}$ & $87,56 a$ & $91,17 \mathrm{a}$ \\
\hline Três meses & $87,08 \mathrm{a}$ & $87,17 \mathrm{a}$ & $87,00 \mathrm{ab}$ \\
\hline CM-424/1 & $84,50 \mathrm{ab}$ & $81,28 \mathrm{ab}$ & $87,72 \mathrm{ab}$ \\
\hline Aipim abacate & $83,03 \mathrm{abc}$ & $83,50 \mathrm{a}$ & $82,56 \mathrm{ab}$ \\
\hline Maragogipe & $82,81 \mathrm{abc}$ & $82,33 \mathrm{ab}$ & $83,28 \mathrm{ab}$ \\
\hline Canário & $78,58 \mathrm{bcd}$ & $77,28 \mathrm{ab}$ & $79,89 \mathrm{ab}$ \\
\hline Caiabana & $76,28 \mathrm{cde}$ & 77,39ab & $75,17 \mathrm{ab}$ \\
\hline MCOL 113 & $75,33 \mathrm{def}$ & $73,44 \mathrm{ab}$ & $77,22 \mathrm{ab}$ \\
\hline Arrebenta burro & $74,64 \mathrm{def}$ & $74,67 \mathrm{ab}$ & $74,61 \mathrm{ab}$ \\
\hline Pão II & 74,44 def & $76,94 \mathrm{ab}$ & $71,94 \mathrm{ab}$ \\
\hline Cachoeiro & $73,00 \mathrm{def}$ & $72,39 \mathrm{ab}$ & $73,61 \mathrm{ab}$ \\
\hline Cabocla & 70,47 efg & $66,28 \mathrm{ab}$ & $74,67 \mathrm{ab}$ \\
\hline Taquari & $68,86 f g$ & $67,78 \mathrm{ab}$ & $69,94 \mathrm{ab}$ \\
\hline PI-939 & $65,89 \mathrm{gh}$ & $69,06 \mathrm{ab}$ & $62,72 \mathrm{ab}$ \\
\hline SM-82/1 & $65,72 \mathrm{gh}$ & $62,17 \mathrm{ab}$ & $69,28 \mathrm{ab}$ \\
\hline Manso & $65,03 \mathrm{ghi}$ & $67,94 \mathrm{ab}$ & $62,11 \mathrm{ab}$ \\
\hline Matrincha & $64,28 \mathrm{ghi}$ & $65,72 \mathrm{ab}$ & $62,83 \mathrm{ab}$ \\
\hline CM-305/1 & $64,22 \mathrm{ghi}$ & $64,00 \mathrm{ab}$ & $64,44 \mathrm{ab}$ \\
\hline Franco Rabelo & 61,89hij & $60,67 \mathrm{ab}$ & $63,11 \mathrm{ab}$ \\
\hline Caravela & $61,69 \mathrm{hij}$ & $61,67 \mathrm{ab}$ & $61,72 \mathrm{ab}$ \\
\hline Sabará & $58,81 \mathrm{ijk}$ & $61,11 \mathrm{ab}$ & $56,50 \mathrm{ab}$ \\
\hline Cenoura rosada & $57,33 \mathrm{jk}$ & $57,33 \mathrm{ab}$ & $57,33 \mathrm{ab}$ \\
\hline Saracura & $54,19 \mathrm{k}$ & $52,78 \mathrm{ab}$ & $55,61 \mathrm{ab}$ \\
\hline Manteiga & $53,33 \mathrm{kl}$ & $53,56 \mathrm{ab}$ & $53,11 \mathrm{ab}$ \\
\hline Amansa burro & $53,17 \mathrm{kl}$ & $54,61 \mathrm{ab}$ & $51,72 b$ \\
\hline IAC-12-442 & 46,641 & $43,50 \mathrm{~b}$ & $49,78 b$ \\
\hline
\end{tabular}

(1)Em cada coluna, médias seguidas da mesma letra não diferem entre si pelo teste de Tukey, a $5 \%$ de probabilidade. 
A análise de correlação foi positiva, entre a matéria seca e o amido $(r=0,9826)$ e, entre a época de colheita e tempo de cocção $(r=0,7304)$. A correlação entre amido e cocção foi negativa $(r=-0,0570)$. Esses resultados indicam que o cozimento não está diretamente relacionado com o teor de amido da raiz.

\section{Conclusões}

1. A produtividade de raízes não apresenta correlação com o teor de matéria seca e de amido em variedades de mandioca de mesa.

2. A variabilidade no cozimento das raízes entre variedades é um fator crítico na seleção de mandioca de mesa.

3. As variedades Três meses e Caiabana são promissoras para consumo humano na forma de raízes frescas, considerando as características como qualidade culinária, produtividade de raízes, teores de cianeto, de matéria seca e de amido.

\section{Agradecimentos}

Ao Conselho Nacional de Desenvolvimento Científico e Tecnológico, pela concessão da bolsa; à Embrapa-Centro Nacional de Pesquisa de Mandioca e Fruticultura Tropical e ao Centro Internacional de Agricultura Tropical, pelo apoio técnico e financeiro.

\section{Referências}

ALMAZAN, A. N. Cyanide concentration in fried cassava chips and its effects on chip taste. Nigerian Food Journal, New York, v. 4, n. 1, p. 65-74, 1986.

BOLHUIS, G. G. The toxicity of cassava roots. Netherlands Journal of Agricultural Science, Wageningen, v. 2, n. 3, p. 176-185, 1954.

BOOTH, R. H. Post-harvest deterioration of tropical root crops: loses and their control. Tropical Science, Oxford, v. 16, n. 2, p. 49-63, 1974.

BOOTH, R. H. Storage of fresh cassava (Manihot esculenta Crantz) I: post-harvest deterioration and its control. Experimental Agriculture, Cambridge, Inglaterra, v. 12, p. 103-111, 1976.

BORGES, M. de F.; CARVALHO, V. D. de; FUKUDA, W. M. G. Efeito de tratamento térmico na conservação pós-colheita de raízes de mandioca (Manihot esculenta
Crantz) de mesa. Revista Brasileira de Mandioca, Cruz das Almas, v. 11, n. 1, p. 7-18, 1992.

BORGES, M. de F.; FUKUDA, W. M. G. Teor de cianeto em raízes frescas e processadas de mandioca (Manihot esculenta Crantz) de mesa. Revista Brasileira de Mandioca, Cruz das Almas, v. 8, n. 2, p. 71-76, 1989.

BORGES, M. de F.; FUKUDA, W. M. G.; CALDAS, R. C. Avaliação de três métodos para determinação de cianeto em mandioca. Revista Brasileira de Mandioca, Cruz das Almas, v. 12, n. 1/2, p. 75-83, 1993.

CARVALHO, V. D. de; CHALFOUN, S. M.; HUEI-WANG, S. Armazenamento pós-colheita de mandioca I: influência da composição química de raízes de cultivares de mandioca sobre a resistência à deterioração pós-colheita fisiológica e microbiológica. Revista Brasileira de Mandioca, Cruz das Almas, v. 1, n. 1, p. 15-23, 1982a.

CARVALHO, V. D. de; CHALFOUN, S. M.; JUSTE JÚNIOR, E. S. G. Métodos de armazenamento na conservação de raízes de mandioca I: efeito da embalagem de polietileno e serragem úmida associada a tratamentos químicos nas deteriorações pós-colheita e qualidade das raízes. Revista Brasileira de Mandioca, Cruz das Almas, v. 4, n. 1, p. 7-18, 1982 b.

CONCEIÇÃO, A. J. da. A mandioca. Cruz das Almas: UFBA/Embrapa-CNPMF/BNB/Brascan Nordeste, 1983. $823 \mathrm{p}$.

CONN, E. E. Cyanogenic glucosides. Journal of Food Chemistry, Washington, v. 17, n. 1, p. 519-526, 1969.

DJAZULI, M.; BRADBURY, J. H. Cyanogen content of cassava roots and flour in Indonesia. Food Chemistry, New York, v. 65, p. 523-525, 1999.

EDIJALA, J. K.; OKOH, P. N.; ANIGORO, R. Chemical assay of cyanide levels of short-time-fermented cassava products in the Abraka area of Delta State, Nigeria. Food Chemistry, New York, v. 64, p. 107-110, 1999.

FUKUDA, W. M. G.; BORGES, M. de F. Avaliação qualitativa de cultivares de mandioca de mesa. Revista Brasileira de Mandioca, Cruz das Almas, v. 7, n. 1, p. 63-71, 1988.

FUKUDA, W. M. G.; BORGES, M. de F. Influência da idade de colheita sobre a qualidade de raízes em diferentes cultivares de mandioca de mesa. Revista Brasileira de Mandioca, Cruz das Almas, v. 9, n. 1/2, p. 7-19, 1990.

FUKUDA, W. M. G.; BORGES, M. de F. Variação do teor e rendimento de farinha de mandioca em função da variedade e idade de colheita. Revista Brasileira de Mandioca, Cruz das Almas, v. 10, n. 1/2, p. 87-94, 1991.

FUKUDA, W. M. G.; SILVA, R. de A.; BORGES, M. de F. Seleção de variedade de mandioca para o consumo 
in natura. Revista Brasileira de Mandioca, Cruz das Almas, v. 7, n. 2, p. 7-18, 1988.

GROSSMAN, J.; FREITAS, A. G. Determinação do teor de matéria seca pelo método do peso específico em raízes de mandioca. Revista Agronômica, Porto Alegre, v. 14, p. 75-80, 1950.

JANSEN, W.; WHEATLEY, C. C. Urban cassava markets. The impact of fresh root storage. Food Policy, Oxford, v. 10 , p. $265-277,1985$.

KATO, M. do S. A. Armazenamento de raízes frescas de mandioca (Manihot esculenta, Crantz) após a colheita. Belém: Embrapa-Uepae de Belém, 1988. 30 p. (Documentos, 5).

LORENZI, J. O.; RAMOS, M. T. B.; MONTEIRO, D. A.; VALLE, T. L.; GODOY JÚNIOR, G. Teor de ácido cianídrico em variedades de mandioca cultivadas em quintais do Estado de São Paulo. Bragantia, Campinas, v. 52, n. 1, p. 1-5, 1993.

MONTALDO, A. Vascular streaking of cassava root tuber. Tropical Science, Oxford, v. 15, n. 1, p. 39-46, 1973.

NORMANHA, E. O. O mau cozimento dos aipins: uma hipótese. Agronômico, Campinas, v. 40, n. 1, p. 13-15, 1988.

O'BRIEN, G. M.; TAYLOR, A. J.; POULTER, N. H. Improved enzymatic assay for cyanogens in fresh and processed cassava. Journal of the Science of Food and Agriculture, London, v. 56, p. 277-289, 1991.
PEREIRA, A. S.; LORENZI, J. O.; VALLE, T. L. Avaliação do tempo de cozimento e padrão de massa cozida em mandioca de mesa. Revista Brasileira de Mandioca, Cruz das Almas, v. 4, n. 1, p. 27-32, 1985.

SANTAMARIA HERNANDEZ, E.; CONTRERAS GUILLEN, J. Composición química de seis variedades de yuca (Manihot esculenta, Crantz) en distintas etapas do desarrollo. Agricultura Técnica en México, México, v. 10, n. 1, p. 316-321, 1984.

SARGENT, S. A.; CÔRREA, T. B. S.; SOARES, A. G. Application of postharvest coatings to fresh cassava roots (Manihot esculenta, Crantz) for reduction of vascular streaking. In: HARVEST AND POSTHARVEST TECHNOLOGIES FOR FRESH FRUITS AND VEGETABLES INTERNATIONAL CONFERENCE, 1995, Guanajuato. Proceedings... Guanajuato: American Society of Agricultural Engineers, 1995. p. 331-338.

TELES, F. F. F. Considerações sobre a análise do ácido cianídrico em mandioca e seus produtos manufaturados. Fortaleza: Etene/BNB, 1972. 24 p.

WHEATLEY, C. C. Conservación de raíces de yuca en bolsas de polietileno. Cali: Centro Internacional de Agricultura Tropical, 1987. 33 p. (Serie 045c-07-06).

WHEATLEY, C. C.; ORREGO, J. I.; SANCHEZ, T.; GRANADOS, E. Quality evaluation of the cassava core collection at CIAT. In: INTERNATIONAL SCIENTIFIC MEETING OF THE CASSAVA BIOTECHNOLOGY NETWORK, 1., 1992, Cartagena. Proceedings... Cali: Centro Internacional de Agricultura Tropical, 1993. p. 255-264. 